\title{
DESCRIÇÃO DO PERFIL PROTEÔMICO DO PLASMA SEMINAL DE ASININOS DA RAÇA PÊGA
}

\author{
Description of proteomic profile of donkey Pêga seminal plasma
}

\section{Descripción del perfil proteomico del plasma seminal de asininos de la raza Pêga}

\section{Laís Ângelo de Abreu ${ }^{* 1}$, Pedro de Almeida Rezende Fumagalli ${ }^{1}$, Thiago} Albuquerque Teles Filho ${ }^{2}$, Fábio Roger Vasconcelos ${ }^{2}$, Luciano Fernandes Sousa ${ }^{1}$, Sandro Estevan Moron ${ }^{4}$, Arlindo de Alencar Araripe Moura ${ }^{2}$, Márcio Gianordoli Teixeira Gomes ${ }^{1}$

${ }^{1}$ Curso de Medicina Veterinária, Universidade Federal do Tocantins, Araguaína -TO, Brasil.

${ }^{2}$ Curso de Zootecnia, Universidade Federal do Ceará, Fortaleza - CE, Brasil.

${ }^{3}$ Programa de Pós-graduação em Medicina Veterinária, Universidade Federal de Viçosa, Viçosa-MG, Brasil

${ }^{4}$ Curso de Zootecnia, Universidade Federal do Tocantins, Araguaína -TO, Brasil

*Correspondência: Laboratório de Embriologia e Genética, Universidade Federal do Tocantins, Rodovia BR-153, Km 112, s/n, Araguaína, Tocantins, Brasil.CEP:77804-970.e-mail laisangeloabreu@ hotmail.com

\section{RESUMO}

A ausência da categoria asinina nas normas técnicas de avaliação seminal promove a necessidade de informações reprodutivas desta espécie. Objetivou-se descrever o perfil proteômico do plasma seminal de jumentos da raça Pêga (Equus asinus). Utilizaram-se seis animais púberes, com peso $239 \pm 32,6 \mathrm{Kg}$ e circunferência escrotal de $36,8 \pm 6,9 \mathrm{~cm}$, criados em mesma propriedade no estado do Tocantins, Brasil. Foi realizada eletroforese unidimensional, utilizando $12,5 \%$ de acrilamida e $30 \mu \mathrm{g}$ de proteína. As bandas foram descoradas e digeridas com tripsina para análise em espectrômetro de massa ESI-Q-TOF. Através de bioinformática, pelo banco de dados UniProtKB, as proteínas foram identificadas. Os termos da ontologia genética foram obtidos a partir do software STRAP ${ }^{\circledR}$. A média da concentração proteica do plasma seminal foi $23,6 \pm 12,6 \mu \mathrm{g} / \mu \mathrm{L}$. Foram detectadas pelo menos 26 bandas por animal (QuantityOne $\left.{ }^{\circledR}\right)$. Um total de 19 bandas e 52 proteínas, com pesos entre 9,51 e 155,9 kDa, foram identificadas pela espectrometria. Os processos biológicos mais relevantes ligados às proteínas identificadas foram a regulação (24\%) e processo celular (22\%). As funções moleculares das proteínas foram descritas como ligação (42\%) e atividade catalítica (31\%). Em conclusão, a existência da descrição do padrão eletroforético destas proteínas plasmáticas seminais contribuirão com a construção de parâmetros para fertilidade.

Palavras-chave: Proteômica, eletroforese, sêmen.

\section{ABSTRACT}

The absence of the asinine category in the technical standards of seminal evaluation, promotes the need for reproductive information of this species. The objective of this study was to describe the proteomic profile of seminal plasma of Pêga donkeys (Equus asinus). Six pubertal animals, weighing 239 $\pm 32.6 \mathrm{Kg}$ and scrotal circumference of $36.8 \pm 6.9 \mathrm{~cm}$, were raised in same farm in the state of Tocantins, Brazil. One-dimensional electrophoresis was performed using $12.5 \%$ acrylamide and $30 \mu \mathrm{g}$ protein. The bands were destained and digested with trypsin for analysis on ESI-Q-TOF mass spectrometer. Through bioinformatics, through the UniProtKB database, the proteins were identified. The terms of the genetic ontology were obtained from the software STRAPß. The mean protein concentration of seminal plasma was $23.6 \pm 12.6 \mu \mathrm{g} / \mu \mathrm{L}$. At least 26 bands per animal were detected (QuantityOne ${ }^{\circledR}$ ). A total of 19 bands and 52 proteins, with weights between 9.51 and $155.9 \mathrm{kDa}$, were identified by spectrometry. The most relevant biological processes related to the identified proteins were regulation (24\%) and cellular process (22\%). The molecular functions of the proteins were described as binding (42\%) and catalytic activity (31\%). In conclusion, the existence of a description of the electrophoretic pattern of these seminal plasma proteins will contribute to the construction of parameters for fertility.

Keywords: Proteomics, electrophoresis, semen. 


\section{RESUMEN}

La ausencia de la categoría asinina en las normas técnicas de evaluación seminal promueve la necesidad de información reproductiva da especie. Se objetivó describir el perfil proteómico del plasma seminal de asnos de la raza Pêga (Equus asinus). Se utilizaron seis animales púberes, con peso 239+32,6 Kg y circunferencia escrotal de $36,8 \pm 6,9 \mathrm{~cm}$, creados en misma granja del estado de Tocantins, Brasil. Se realizó una electroforesis unidimensional, utilizando $12,5 \%$ de acrilamida y $30 \mu \mathrm{g}$ de proteina. Las bandas fueron blanqueadas y digeridas con tripsina para análisis en espectrómetro de masa ESI-Q-TOF. Através de bioinformática, por la base de datos UniProtKB, las proteínas fueron identificadas. Los términos de la ontología genética se obtuvieron a partir del software STRAP®. La media de la concentración proteica del plasma seminal fue de 23,6 $\pm 12,6 \mu \mathrm{g} / \mu \mathrm{L}$. Se detectaron al menos 26 bandas por animal (QuantityOne $\left.{ }^{\circledR}\right)$. Un total de 19 bandas y 52 proteínas, con pesos entre 9,51 y 155,9 kDa, fueron identificadas por la espectrometría. Los procesos biológicos más relevantes relacionados con las proteínas fueron la regulación (24\%) y el proceso celular (22\%). Las funciones moleculares se describieron como enlace (42\%) y actividad catalítica (31\%). En conclusión, la existencia de la descripción del patrón electroforético de estas proteínas plasmáticas seminales contribuirán a la construcción de parámetros para la fertilidad.

Descriptores: Proteómica, electroforesis, semen.

\section{INTRODUÇÃO}

O Brasil ocupa o $12^{\circ}$ lugar entre os países com maior população de asininos, com estimativa de 915.000 cabeças (FAO, 2013). De acordo com o IBGE (2012), o Nordeste apresenta $47 \%$ da população, seguida pelo Sudeste (19\%) e Norte (15\%). Dentre as raças criadas no país, encontram-se os jumentos Paulista, Nordestino e Pêga.

Conforme a Associação Brasileira de Criadores de Jumentos Pêga, em 2013, haviam 28.349 animais registrados, sendo a raça mais utilizada para o cruzamento com éguas, visando à produção de muares marchadores (NUNES, 2007). O Brasil, por sua vez, ocupa o terceiro lugar na população mundial de muares, atingindo cerca de 1.239.000 animais de 10.172.586 cabeças mundiais (FAO, 2013).

A eficiência reprodutiva constitui um dos principais objetivos de seleção utilizada nos atuais sistemas de produção animal, por ser um dos fatores essenciais para a lucratividade (MATOS et al., 1992). Diversos critérios têm sido utilizados para buscar indicadores confiáveis do potencial reprodutivo dos animais, incluindo medições da biometria testicular, avaliação da motilidade e defeitos morfológicos, análise computadorizada do sêmen e testes avançados de função espermática (SOUZA et al., 2001; SOUZA,
2007). No entanto, apesar destas avaliações definirem critérios mínimos para a seleção e utilização de reprodutores, as mesmas não apresentam relação significativa com a fertilidade dos animais (AMANN; HAMMARSTEDT, 1993).

Pela ciência da reprodução animal, sabe-se que mudanças bioquímicas ocorrem com os espermatozoides, entre a ejaculação e a fertilização, sendo que para estes chegarem ao oócito é necessário atravessar todo o trato reprodutivo feminino e nesse processo, as proteínas plasmáticas seminais tem grande atuação na proteção das células germinativas.

A limitação dos testes comuns para se determinar a fertilidade de um animal pode estar relacionada ao fato de que estes exames não levam em consideração a habilidade dos espermatozoides de sofrer alterações funcionais importantes para o processo de fertilização (AMMAN; HAMMARSTEDT, 1993). Conforme Moura et al., (2006) apud Rego (2010) estudos recentes têm apontado uma relação entre a expressão de proteínas no trato reprodutivo e a fertilidade dos reprodutores.

De acordo com Rego (2010) o plasma seminal é composto por fluídos oriundos dos testículos, epidídimos e glândulas sexuais acessórias e serve como meio de transporte para os espermatozoides e 
contribui para sua sobrevivência no trato reprodutivo feminino (EVANS; MAXWELL, 1987).

Durante a ejaculação os espermatozoides adquirem inúmeras proteínas que podem influenciar sua fertilidade (YANAGIMACHI, 1994 apud REGO, 2010). Estas proteínas foram associadas a características como, capacidade de produção espermática (MÉTAYER et al., 2001), motilidade (DIAMANDIS et al., 1999), morfologia (DE KRETSER; KERR, 1994) e até mesmo a proteção das células espermáticas contra danos oxidativos (SCHÖNECH et al., 1996).

O Colégio Brasileiro de Reprodução Animal (CBRA, 1998) estabeleceu padrões e normas para a avaliação do sêmen e exame andrológico de algumas espécies domésticas, todavia não incluindo os asininos nesses padrões (CANISSO et al., 2008), o que promove extrema relevância à trabalhos que consistam na construção de informações sobre os parâmetros reprodutivos desta espécie; como os exames de biometria testicular, características espermáticas e a análise do plasma seminal. O mapeamento proteômico do plasma seminal pode ser realizado pelo método de eletroforese em gel de poliacrilamida.

Para determinar a massa de proteínas, através do método de eletroforese, uma amostra contendo uma mistura de proteínas com massas conhecidas, os marcadores de peso molecular, devem ser adicionados no mesmo gel. Posteriormente, cora-se o gel e medese a distância percorrida por cada proteína (WILSON \& WALKER, 2010). O presente trabalho objetivou caracterizar as proteínas do plasma seminal de asininos da raça Pêga, utilizando a técnica de eletroforese unidimensional, e correlacionar as mesmas com possíveis parâmetros espermáticos.

\section{MATERIAIS E MÉTODOS}

Foram utilizados seis $(n=6)$ jumentos da raça Pêga, púberes, com média de peso $239 \pm 32,6 \mathrm{Kg}$ e circunferência escrotal de $36,8 \pm 6,9 \mathrm{~cm}$, sob condições uniformes de manejo e nutrição, pertencentes a mesma propriedade, no estado do Tocantins, Brasil. As avaliações de concentração e morfologia espermática foram realizadas no Laboratório de Morfofisiologia e Bioquímica de Peixes Neotropicais da Universidade Federal do Tocantins e as análises seminais plasmáticas foram executadas no Laboratório de Fisiologia Animal da Universidade Federal do Ceará.

As coletas de sêmen foram realizadas através de vagina artificial, com temperatura média de $39,5^{\circ} \mathrm{C}$. Uma alíquota de $20 \mu \mathrm{L}$ de cada amostra foi retirada para análise dos parâmetros seminais, incluindo vigor, porcentagem de espermatozoides móveis e motilidade progressiva (MAXWELL et al., 1997). Posteriormente, as amostras de sêmen foram centrifugadas a $600 \times \mathrm{g}$ durante 10 minutos, e ao plasma seminal obtido, foi adicionado inibidor de protease (1:1000), sendo acondicionadas em criotubos, e por fim, em nitrogênio líquido.

Para a contagem dos espermatozoides, o sêmen foi diluído em solução salina fisiológica formolizada a $1 \%$ na proporção de 1:50 e analisados em câmara de Neubauer. A morfologia espermática foi analisada sob microscópio com contraste de fase em objetiva de 100x.

As proteínas do plasma seminal foram quantificadas; através da construção de uma curva analítica de calibração. Para cada amostra de plasma seminal foram feitas alíquotas triplicatas e a curva de calibração foi estabelecida pelas médias das triplicatas das absorbâncias obtidas, gerando uma equação linear de absorbância versus concentração (REGO, 2010).

A partir de uma alíquota com $98 \mu \mathrm{L}$ de PBS, $1 \mathrm{~mL}$ do reagente de Bradford (BRADFORD, 1976) e $2 \mu \mathrm{L}$ de plasma seminal foram obtidas as duas alíquotas posteriores, que constituem-se em $20 \mu \mathrm{L}$ da solução da primeira somado a $1 \mathrm{~mL}$ do reagente de 
Bradford. Após 10 minutos, leituras em $595 \mathrm{~nm}$ foram feitas e a média das triplicatas usadas para o cálculo do teor de proteína de cada amostra.

As amostras de plasma seminal foram submetidas à eletroforese unidimensional, utilizando malha 12\%; constituído por $20,9 \mathrm{~mL}$ de acrilamida, $12,5 \mathrm{~mL}$ de TRIS-HCl (pH 8,8 e 1,5M), 0,5 mL de SDS $10 \% ; 15,87 \mathrm{~mL}$ de água destilada; $0,277 \mathrm{~mL}$ de persulfato de amônio e $20 \mu \mathrm{L}$ de TEMED. As proteínas foram desnaturadas, por descongelamento, e ajustadas para $30 \mu \mathrm{L}$. A cuba foi preenchida com Tampão 10X e a corrida do gel foi mantida em $500 \mathrm{~V}, 75 \mathrm{~mA}$ e $90 \mathrm{~W}$.

Os géis foram corados com Coomassie Blue coloidal $2 \%$, as imagens digitalizadas utilizando o ImageScanner II (GE Lifesciences, USA) e analisadas através do software Quantity One ${ }^{\circledR}$ (Bio Rad, USA). As bandas identificadas foram descoradas e digeridas com tripsina para análise em espectrômetro de massa ESI-Q-TOF. Através de bioinformática, as proteínas foram identificadas utilizando banco de dados UniProtKB e os termos da ontologia genética foram obtidos a partir do software STRAP ${ }^{\circledR}$.

\section{RESULTADOS E DISCUSSÃO}

O sêmen apresentou aspecto variável entre os animais, seroso ou leitoso, e volume de $44,1 \pm 38,1 \mathrm{~mL}$. Para a realização das avaliações espermáticas, face a ausência de parâmetros exclusivos para asininos, adotou-se a metodologia para equinos (CBRA, 2013), revelando assim, concentração de $345,4 \pm 269,7 \times 10^{6}$ espermatozoides $/ \mathrm{mL}$, vigor $4 \pm 0,7$ e $77 \% \pm 0,1$ de motilidade espermática progressiva. $\mathrm{O}$ número de espermatozoides normais foi de $82 \pm 0,16 \%$, seguido por $9 \pm 0,04 \%$ de defeitos menores e $9 \pm 014 \%$ de defeitos maiores.

A avaliação das amostras de sêmen demonstraram que os animais púberes utilizados neste estudo possuíam capacidade reprodutiva normal, baseado na média da concentração e motilidade espermática, além de possuírem fertilidade comprovada em sistemas de monta controlada.

A média da concentração proteica do plasma seminal foi $23,6 \pm 12,6 \mu \mathrm{g} / \mu \mathrm{l}$, número maior quando comparado a ovinos $(18,08 \mu \mathrm{g} / \mu \mathrm{l})$ conforme o trabalho de Silva (2010), porém significativamente menor em relação ao trabalho de Moura (2010), que revelou concentração de até $38,37 \mu \mathrm{g} / \mu \mathrm{l}$ em ovinos. Foram detectadas pelo menos 26 bandas por animal (Quantity One $\left.e^{\circledR}\right)$. Um total de 19 bandas e 52 proteínas, com pesos entre 9,51 e 155,9 kDa, foram identificadas por espectrometria de massa.

Algumas das proteínas detectadas foram; hypoxia up-regulated protein 1, que exerce papel fundamental nos mecanismos celulares citoprotetores desencadeados pela privação de oxigênio; heat shock cognate 71 kDa protein 1, que atua na proteção do proteoma celular contra o estresse térmico; seminal plasma protein HSP-1, relacionada com a capacidade de fertilização dos espermatozoides, uma vez que interage com glicosaminoglicanos presentes no trato genital feminino; sperm-associated acrosin inhibitor, que por sua vez, inibe a acrosina, que é liberada pela membrana acrossômica interna e facilita a penetração do espermatozoide na zona pelúcida.

Os processos biológicos mais relevantes ligados às proteínas identificadas foram a regulação (24\%) seguida por processo celular (22\%) (Figura 1). Estes demonstram as reações químicas das proteínas, que podem desencadear transformações. 
Figura 1: Processo biológico das proteínas do plasma seminal do Jumento (Equus asinus) da raça Pêga.

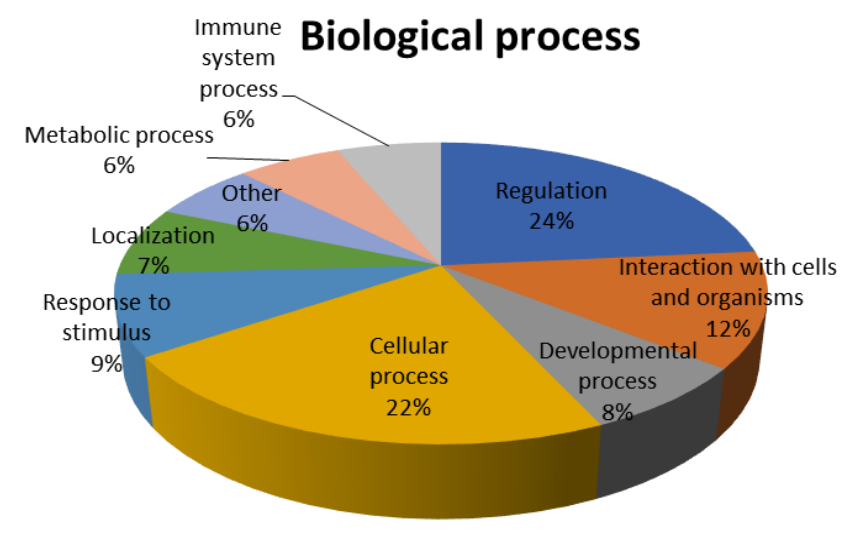

As funções moleculares das proteínas (26\%), fator que pode ser influenciado pelo foram descritas como ligação (42\%) e atividade catalítica (31\%) (Figura 2). Os componentes método de coleta seminal, citoplasmáticos $(12 \%)$ celulares mais abundantes foram extracelulares e complexos macromoleculares (9\%) (Figura 3).

Figura 2: Função molecular das proteínas do plasma seminal do Jumento (Equus asinus) da raça Pêga.

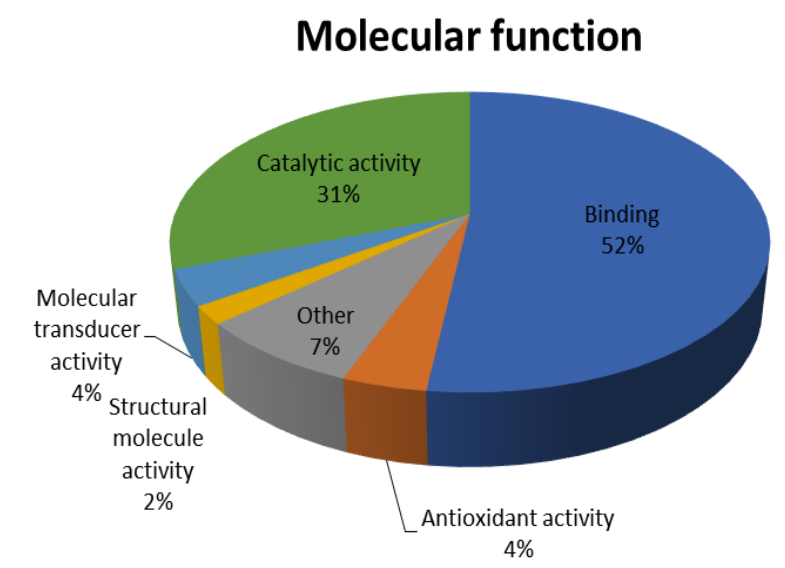

Figura 3: Componente celular das proteínas do plasma seminal do Jumento (Equus asinus) da raça Pêga.

\section{Cellular component}

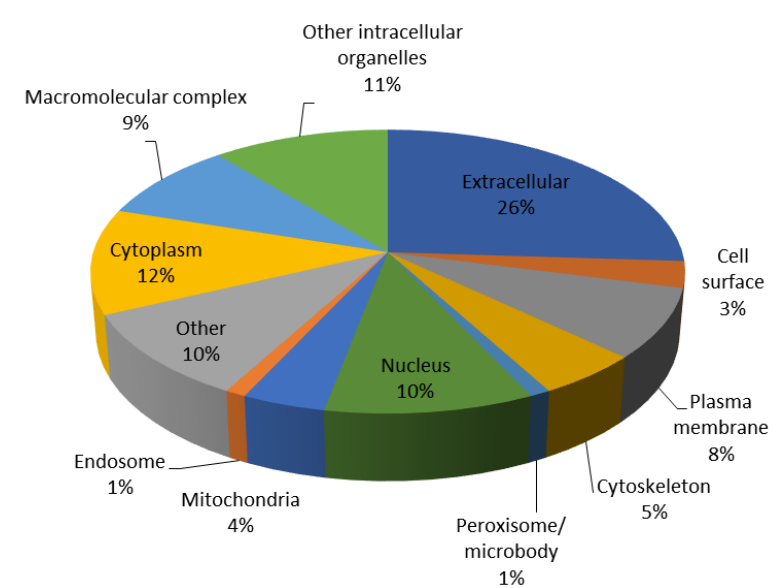

$1 \%$ 


\section{CONCLUSÃO}

Utilizando uma abordagem proteômica foi possível a identificação do perfil eletroforético das proteínas do plasma seminal de jumentos da raça Pêga. A posterior análise destas proteínas e suas características poderão alicerçar os estudos sobre a fisiologia reprodutiva básica desses animais, o que possibilita a associação das proteínas seminais com parâmetros espermáticos, identificação de marcadores moleculares para fertilidade e possíveis comparações com a espécie equina; podendo auxiliar futuramente na seleção de reprodutores mais férteis.

\section{AGRADECIMENTO}

O presente trabalho foi realizado com o apoio do Conselho Nacional de Desenvolvimento Científico e Tecnológico (CNPq - Brasil).

Agradecemos a fazenda RAF (Araguaína TO), pelo fornecimento dos animais para a execução deste trabalho.

Todos os autores declararam não haver qualquer potencial conflito de interesses referente a este artigo.

\section{REFERÊNCIAS}

AMMAN, R. P; HAMMERSTEDT, R. H. In Vitro Evaluation of Sperm Quality: An Opinion. Journal of Andrology, vol. 14, n. 6, p. 397-406, 1993.

BRADFORD, M.M. A rapid and sensitive method for the quantization of microgram quantities of protein utilizing the principle of dye binding. Anal Biochem, v.72, 248-254, 1976.

CANISSO, I.F. et al. Alguns aspectos fundamentais do exame clinico andrológico de jumentos (Equus asinus). Rev Bras Reprod Animal, (in press), 2008.

CBRA (Colégio Brasileiro de Reprodução Animal). Manual para exame andrológico e avaliação de sêmen animal. 2.ed. Belo Horizonte; 54p, 1998.

CBRA (Colégio Brasileiro de Reprodução Animal). Manual para exame andrológico e avaliação de sêmen animal. 3.ed. Belo Horizonte; 87p, 2013.

DE KRETSER, D.M.; KERR, J.B. The cytology of the testis. In: KNOBIL, E.; NEILL, J. (eds.) The Physiology of Reproduction, New York: Raven Press, p. 1177-1290, 1994.

DIAMANDIS, E.P; ARNETT, W.P; FOUSSIAS, G; PAPPAS, H; GHANDI, S; MELEGOS, D.N; MULLEN, B; YU, H.; SRIGLEY, J; JARVI, K. Seminal plasma biochemical markers and their association with semen analysis findings. Adult Urology. Elsevier Science Inc., 3 ed., p. 596-603, v. 53, 1999.

EVANS, G. \& MAXWELL, W.M.A. Salamon's artificial insemination of sheep of goats. Sydney, Butterworths, p.194, 1987.

FAO. FOOD AND AGRICULTURE ORGANIZATION. Production of 2013. <http://faostat.fao.org>. Acesso em 20 de abril de 2014.

IBGE. INSTITUTO BRASILEIRO DE GEOGRAFIA E ESTATÍSTICA. Produção da Pecuária Municipal. Brasil, p. 67, 2012.

MATOS, D.G., MOSES, D.F., de las HERAS, M.A., et al. Minimal time required in contact with glyce rol for cryopreservation of ram semen. In: INTERNATIONAL. CONGRESS. ON ANIMAL. REPRODUCTION, 12, 1992, The Hague. Proc... The Hague: International Congress on Animal Reproduction, 1992, v. 3, p.1401-1403.

MAXWELL, W. M. C.; WELCH, R.; JOHNSON, L. A. Viability and membrane integrity of spermatozoa after dilution and flow cytometric sorting in the presence or absence of seminal plasma. Reprod Fertil Dev, 8, 1165-1178, 1997.

MÉTAYER, S.; DACHEUX, F.; DACHEUX, J.L. et al. Comparison, characterization, and identification of proteases and proteases inhibitors in epididimal fluid of domestic animals: matrix metalloproteinases are major fluid gelatinases. Biology of Reproduction, v.66, p.1219-1229, 2002.

MOURA, A. A.; CHAPMAN, D. A. KOC, H.; KILLIAN, G. J. A comprehensive proteomic analysis of the accessory sex gland fluid from mature Holstein bulls. Anim Reprod Sci, in press 2006. In: REGO, J.P.A. Análise proteômica do plasma seminal de carneiros Santa Inês adultos. Dissertação (Mestrado). Fortaleza-CE, 2010. 
MOURA, P.P.; FRANCO, M.M.; SILVA, T.A.S.N.; ROCHA, T.L.; LEAL, D.R.; PASSOS, P.I.B.; NEVES, J.P. Caracterização de proteínas do plasma seminal e sua relação com parâmetros de qualidade do sêmen criopreservado em ovinos. Ciência Rural, Santa Maria, 2010.

NUNES, R. O Jumento Pêga. In: CARVALHO, G.R.; SIMPÓSIO MINEIRO DE EQÜIDEOCULTURA, Viçosa, MG. Anais.Viçosa: Universidade Federal de Viçosa, v.1, n.1, p.20-31, 2007.

REGO, J.P.A. Análise proteômica do plasma seminal de carneiros Santa Inês adultos. Dissertação (Mestrado). Fortaleza - CE, 2010.

SCHÖNECH, C., BRAUN, J., EINSPANIER, R. Sperm viability is influenced in vitro by the bovine seminal protein aSPF: effects on motility, mitochondrial activity and lipid peroxidation. Theriogenology, Amsterdam v.45, p.633-642, 1996.

SILVA, N.M.M; ELOY, A.M.X; PINHEIRO, R.R; VALLE, R.V; FURTADO, J.R; SILVA, N.M. Proteínas do plasma seminal e sua relação com a fertilidade de ovinos da raça morada nova no período chuvoso. XX Congresso Brasileiro de Zootecnia, 2010.

SOUZA, C. E. A.; MOURA, A. A.; LIMA, A. C. B. Circunferência escrotal e características seminais em carneiros Santa Inês. Revista Brasileira de Reprodução Animal, Belo Horizonte, v. 25, n. 2, p.196-198, 2001.

SOUZA, C.E.A. Análise proteômica do plasma seminal e secreções do epidídimo em ruminantes: potenciais associações com o desenvolvimento sexual, parâmetros seminais e função espermática. Tese (Doutorado). Fortaleza - CE, 2007.

WILSON, K; WALKER, J. Principles and techniques of biochemistry and molecular biology. Cambridge University Press, 7th ed., 2010.

YANAGIMACHI, R. Mammalian fertilization, Chapter 5. In: The physiology of Reproduction. Knobil E, Neill J. D. (eds). Raven Press, Ltd, NewYork, 1994 pp.189-317. 